\title{
Psyllid Biology: Expressed Genes in Adult Asian Citrus Psyllids, Diaphorina citri Kuwayama
}

\author{
W.B. Hunter*,1, S.E. Dowd ${ }^{2}$, C.S. Katsar ${ }^{3}$, R.G. Shatters ${ }^{1}$ Jr., C.L. McKenzie ${ }^{1}$ and D.G. Hall ${ }^{1}$ \\ ${ }^{I}$ United States Department of Agriculture, Agricultural Research Service, United States Horticultural Research Labora- \\ tory, Fort Pierce, Florida, USA; ${ }^{2}$ United States Department of Agriculture, Agricultural Research Service, Cropping \\ Systems Research Laboratory, Lubbock, Texas, USA; ${ }^{3}$ United States Department of Agriculture, Animal and Plant \\ Health Inspection Service, Plant Protection and Quarantine, Fort Lauderdale, Florida, USA
}

\begin{abstract}
Where it occurs the Asian citrus psyllid, Diaphorina citri, Kuwayama (Hemiptera: Psyllidae) is considered the primary vector of Huanglongbing, HLB, disease of citrus trees. The plant pathogenic bacterium associated with HLB causes economic losses to citrus industries worldwide. To better understand the general biology of $D$. citri, we undertook a sequencing project from adult psyllids. Few genes have been isolated from psyllids however several insect genomic datasets are available for comparisons. We compared the psyllid data to genomic datasets of nematode, C. elegans, fruit fly, D. melanogaster, honey bee, A. mellifera, mosquito, A. aegypti, and human, $H$. sapiens since these have completed more thorough levels of annotation. We describe the first data set of ESTs from D. citri, the Asian citrus psyllid. A total of 5,906 cDNA clones were sequenced, resulting in 4,595 high-quality ESTs. Electronic removal of 1,487 sequences which matched to bacteria and viruses left an assembly of cDNAs resulting in a total of 636 psyllid sequences (544 contigs plus 92 singlets). The sequences underwent BLAST analyses using (Swissprot-Tremble 03-2007) and NCBI, nr databases which returned $53 \%$ with 'No significant match' in either the non-redundant protein or nucleic acid databases, providing new information to the scientific community. The $D$. citri gene expression data set advances current research efforts in the identification of genes and physiological processes of psyllids. Knowledge of these genes and proteins are being used in the development of novel management strategies against psyllids, and other sap feeding insects within the Order: Hemiptera.
\end{abstract}

Keywords: ACP, AsCP, Diaphorina citri, EST, Genome, Hemiptera, Huanglongbing, Psyllid.

The use or mention of a trademark or proprietary product does not constitute an endorsement, guarantee, or warranty of the product by the U.S. Department of Agriculture and does not imply its approval to the exclusion of other suitable products.

\section{INTRODUCTION}

The Asian citrus psyllid, Diaphorina citri, Kuwayama (Hemiptera: Psyllidae), is a major pest of citrus causing damage through feeding, but more importantly as the vector of the most serious disease of citrus, referred to as Huanglongbing, HLB [1]. Huanglongbing disease is associated with the plant pathogenic bacterium, Candidatus Liberibacter asiaticus, [2, 3]. Diaphorina citri was first reported in Florida in 1998 and has since spread throughout Florida [4]. In 2005, HLB disease was reported to be in Florida [5]. The pathogen, a phloem-restricted alpha-proteobacterium [6] is associated with HLB which has been referred to by several names: in India as 'Citrus Dieback', more commonly referred to as 'Citrus Greening' a term used more broadly around the world, and 'Huanglongbing', HLB, or 'Yellow Dragon Disease' in China $[1,7]$. The importance of D. citri as the vector of HLB prompted the need for a better understanding of psyllid biology. Since the genomic sequence of D. citri was not available, we produced expressed sequence tags (ESTs) from adult $D$. citri. Sequence tags offered an

*Address correspondence to this author at the United States Department of Agriculture, Agricultural Research Service, United States Horticultural Research Laboratory, Fort Pierce, Florida, USA;

E-mail: Wayne.Hunter@ARS.USDA.GOV invaluable resource for the identification of genes associated with the specific biology of psyllids [8-10]. Application of a transcriptome approach has also led to other important discoveries such as insect pathogens, as in the discovery of the first virus in $D$. citri [11], the first viral pathogens of the red imported fire ant $[12,13]$ and viruses in the glassy-winged sharpshooter, Homalodisca coagulata virus 1 , HoCV- 1 [14, 15], the discovery and identification of genes linked to the development and reproduction of aphids [16, 17], and in discoveries made in the studies of the specialized cells that harbor aphid endosymbionts [18, 19]. Additionally, ESTs and their accompanying cDNAs provide the means to construct arrays that can be used for transcript profiling on a genome-wide scale [20-23]. However, even without subsequent array analyses, a relatively large number of ESTs from a specific life stage provides clues toward the expression of specific genes important to the functions connected with that life stage [24-26]. Examination of transcriptome data sets, within statistical limitations, and in most cases, have shown that the abundance of a specific cDNA in the EST collection is a measure of gene expression [27] providing a "digital or electronic northern" that has been utilized to gauge relative gene expression in various tissues and can often direct the efforts of researchers towards genes of interest. Genetic information on hemipterans still lags behind that for other insects, thus it was essential to build an expression library de- 
rived from adult $D$. citri so that analyses of metabolism on a genome-wide scale could begin.

\section{MATERIALS AND METHODS}

\section{Psyllid Rearing and Collection}

Asian citrus psyllids, D. citri, were obtained from a colony established from field caught adults, maintained by C.L. McKenzie at the USDA, ARS, U.S. Horticultural Research Laboratory, Ft. Pierce, FL. Insects were reared on Murraya paniculata (L.) 'Orange-jasmine' seedlings in screen cages contained in an insectary, and held at $25^{\circ} \mathrm{C}, 16 \mathrm{~L}: 8 \mathrm{D}$. Plants with new flush were cycled into cages on a weekly basis. High-density psyllid populations produced psyllids that were collected by aspiration; the adults collected were immediately submerged into liquid nitrogen prior to total RNA isolation.

\section{cDNA Library Construction}

Approximately 3,500 adult psyllids of mixed age and genders were used in the construction of an expression library. Whole psyllids were ground in liquid nitrogen and total RNA extracted using guanidinium salt-phenolchloroform procedure as previously described by Strommer et al. [28]. Poly(A) + RNA was purified using two rounds of selection on oligo dT magnetic beads according to the manufacturer's instructions (Dynal, Oslo, Norway). cDNA was synthesized using Stratagene's ZAP-cDNA Synthesis Kit (Stratagene, La Jolla, CA, USA). Mass excision of the amplified library was carried out using Ex-Assist helper phage (Stratagene, La Jolla, CA, USA) and bacterial clones containing excised pBluescript $\mathrm{SK}(+)$ phagemids were recovered by random colony selection.

\section{Sequencing of Clones}

pBluescript $\mathrm{SK}(+)$ phagemids were isolated from cell cultures grown overnight in 96-deep well plates containing $1.8 \mathrm{~mL}$ of $\mathrm{LB}$, supplemented with $100 \mu \mathrm{g} / \mathrm{mL}$ ampicillin. DNA was extracted using the Qiagen 9600 liquid handling robot and the QIAprep 96 Turbo miniprep kit according to the recommended protocol (QIAGEN Inc., Valencia, CA, USA). Sequencing reactions were performed using the ABI PRISM BigDye ${ }^{\mathrm{TM}}$ Primer Cycle Sequencing Kit (Applied Biosystems, Foster City, CA, USA). Reactions were prepared in 96-well format using the Biomek2000 ${ }^{\mathrm{TM}}$ liquid handling robot (Beckman Coulter, Inc., USA). Sequencing reaction products were precipitated with $70 \%$ isopropanol, resuspended in $15 \mu \mathrm{L}$ sterile water and loaded onto an ABI 3730 DNA Analyzer (Applied Biosystems, Foster City, CA, USA).

\section{Computer Analysis}

ESTs were generated from single-pass $5^{\prime}$ end sequencing of the $D$. citri expression library. Base calling, quality trimming, vector trimming and sequence fragment alignments were performed by SeqMan Pro (DNAstar, USA). Lowquality bases (quality score <12) were trimmed from both ends of sequences. Assembly parameters were set using a minimum overlap of $30 \mathrm{bp}$, match spacing of $150 \mathrm{bp}$ minimum sequence length and 90\% identity. Putative sequence identity was determined based on BLAST similarity searches (BLASTX and BLASTn) using WND.BLAST Dowd, against Uniprot (Dec2007), and NCBI, nr database. We compared the psyllid data to genomic datasets of nematode, C. elegans, fruit fly, D. melanogaster, honey bee, A. mellifera, mosquito, $A$. aegypti, and human, $H$. sapien since these have a higher level of completed annotations. (http://www. ncbi.nlm.nih.gov/genomes/; http://www.vectorbase.org/index. php;). A set of the originally described ESTs (4,595 were used for the current analyses) from adult $D$. citri which is available at GenBank, dbEST, for further studies, Accession numbers: DN201110-DN470410. GenBank http://www.ncbi. nlm.nih.gov

\section{RESULTS}

\section{Identification of ESTs}

Of the 5, 906 ESTs from the D. citri expression library, 4,595 ESTs were identified with lengths greater than 150 nucleotides subsequent to quality and vector trimming with an average length of 553 bases. Because multiple ESTs can be derived from a single gene, sequences were assembled into contigs to estimate the number of genes giving rise to the ESTs. Electronic removal of 1,487 sequences which matched to bacteria and viruses left a total assembly of 636 cDNAs from psyllid (544 contigs plus 92 singlets) (refer to Table 1 for the most abundant contigs). Thus this represents the maximal number of 'Psyllid unique' assembled sequences. Of that total, 299 of the contigs and singlets corresponded with a putative match in GenBank, while 337 of the cDNAs had 'No Significant Homology' to any sequence currently listed in GenBank. 'No Significant Homology' denotes a 'no match' to GenBank's database when similarity or identity searches were performed using BLASTX, and BLASTN, with an $\mathrm{E}$ value $<1^{-10}$. The unknown $53 \%$ of the cDNAs is due to the large number of unknown proteins still to be characterized in insects, especially in Hemiptera which are a more ancient lineage thus they may have a more diverse transcriptome (Fig. 1). To examine the uniqueness within this psyllid dataset a comparison to five other genomic datasets (Table 4); nematode, Caenorhabditis elegans, fruit fly, Drosophila melanogaster, honey bee, Apis mellifera, mosquito, Aedes aegypti, and human, Homo sapiens provided a distribution across established classes of putative functions based on homology to proteins that had been previously characterized in the NCBI database (Tables 1,

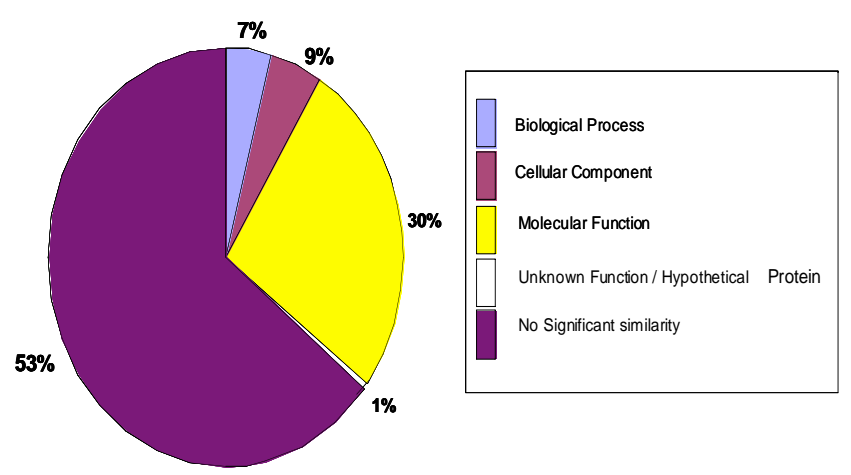

Fig. (1). Proportion of unassembled sequences from the Asian Citrus Psyllid EST dataset sorted using Gene Ontology. 53\% of the cDNA's had 'No Significant Homology' to any known protein or nucleotides in the GenBank non-redundant database, BLASTX analysis at $E$-value of $\leq-10$. NCBI, http://www.ncbi.nlm.nih.gov/. 
Table 1. Twenty Most Frequently Represented EST Sequences in Asian Citrus Psyllid

\begin{tabular}{|c|c|c|c|c|}
\hline Sequence ID & Description $^{\mathrm{a}}$ & Best Match $^{\text {b }}$ & E.C.\# & E Value \\
\hline WHDc 0014 & Cytochrome $\mathrm{c}$ oxidase subunit I & Q69HD6 & 1.9.3.1 & $1.5035 \mathrm{E}-150$ \\
\hline WHDc 0080 & Cytochrome c oxidase subunit III & Q69HD2 & 1.9.3.1 & $5.07862 \mathrm{E}-46$ \\
\hline WHDc 0021 & Putative ferritin GF2 & Q6PPI2 & & 7.47398E-63 \\
\hline WHDc 0023 & Cytochrome $\mathrm{c}$ oxidase subunit II & Q69HD5 & 1.9.3.1 & 9.85564E-77 \\
\hline WHDc 0065 & myosin light chain & Q7PUV3 & & $8.0000 \mathrm{E}-48$ \\
\hline WHDc 0076 & ATP synthase F0 subunit 6 & Q69HD3 & & 6.18037E-06 \\
\hline WHDc 0187 & Translationally controlled tumor protein & Q75VN3 & & $1.85962 \mathrm{E}-80$ \\
\hline WHDc 0020 & NADH dehydrogenase subunit 5 & Q69HD0 & 1.6.5.3 & $2.06965 \mathrm{E}-80$ \\
\hline WHDc 1078 & Ribosomal protein $\mathrm{L} 32$ & Q6F449 & 3.6.5.3 & 2.37581E-49 \\
\hline WHDc 0049 & S3e ribosomal protein & Q6EV05 & 3.6.5.3 & 2.6657E-100 \\
\hline WHDc 0175 & NADH dehydrogenase subunit 1 & Q68RL0 & & 7.91356E-87 \\
\hline WHDc 0177 & Thioredoxin-like protein & Q9U515 & & 2.38394E-19 \\
\hline WHDc 0441 & Ribosomal protein S27 & Q962Q3 & 3.6.5.3 & 3.31106E-41 \\
\hline
\end{tabular}

${ }^{\mathrm{a} D e s c r i p t i o n}$ derived from GenBank $\mathrm{nr}$ database BLASTX search. ${ }^{5}$ EST match indicates the gi number of the most similar annotated cDNA in GenBank nr database, BLASTX analysis matches had an $E$-value of $\leq-10$. NCBI.

\section{Table 2. Biological Process}

\begin{tabular}{|l|l|}
\hline Gene Ontology Term & \# Hits \\
\hline \hline ATP biosynthesis & 2 \\
\hline ATP synthesis coupled proton transport & 4 \\
\hline Biological process unknown & 3 \\
\hline Carbohydrate metabolism & 2 \\
\hline cation transport & 1 \\
\hline cell adhesion & 3 \\
\hline cell cycle & 1 \\
\hline compound eye morphogenesis (sensu Endopterygota) & 1 \\
\hline Cytokinesis & 3 \\
\hline detection of virus & 1 \\
\hline Electron transport & 9 \\
\hline fatty acid alpha-oxidation & 1 \\
\hline fatty acid metabolism & 1 \\
\hline
\end{tabular}




\begin{tabular}{|c|c|}
\hline Gene Ontology Term & \# Hits \\
\hline Immune response & 1 \\
\hline intracellular protein transport & 4 \\
\hline larval or pupal development (sensu Insecta) & 1 \\
\hline Metabolism & 5 \\
\hline polysaccharide catabolism & 1 \\
\hline protein deneddylation & 1 \\
\hline protein import into nucleus, docking & 1 \\
\hline Proteolysis & 1 \\
\hline Regulation of progression through cell cycle & 1 \\
\hline ribonucleoside diphosphate catabolism & 1 \\
\hline Ribosomal large subunit assembly and maintenance & 1 \\
\hline rRNA modification & 1 \\
\hline Salivary gland cell autophagic cell death & 1 \\
\hline selenocysteine incorporation & 1 \\
\hline signal transduction & 1 \\
\hline tetrahydrobiopterin biosynthesis & 1 \\
\hline Transport & 1 \\
\hline Two-component signal transduction system (phosphorelay) & 2 \\
\hline Type I hypersensitivity & 1 \\
\hline Total & 59 \\
\hline
\end{tabular}

Functional assignments of Psyllid EST unassembled sequences described are inferred from electronic evidence using top 5 BLASTX hits with an $E$-value of $\leq-10$ generated from NCBI's nr database. Definition term associated with each sequence defined according to The Gene Ontology Consortium.

\section{Table 3. Molecular Function}

\begin{tabular}{|l|l|l|l|}
\hline Gene Ontology Term ${ }^{\text {(Parent) }}$ & \# Hits & Gene Ontology Term ${ }^{\text {a }}$ (Child) & \# Hits \\
\hline \hline 2-dehydro-3-deoxygluconokinase activity & 1 & & \\
\hline 3'-5'-exoribonuclease activity & 2 & & \\
\hline 4-alpha-hydroxytetrahydrobiopterin activity & 1 & & \\
\hline 5-aminolevulinate synthase activity & 1 & & \\
\hline 6-pyruvoyltetrahydropterin synthase activity & 1 & & \\
\hline acid phosphatase activity & 1 & & \\
\hline Actin binding & 1 & & \\
\hline acyl-CoA dehydrogenase activity & 1 & & \\
\hline Acyltransferase activity & 1 & 1 & \\
\hline adenine phosphoribosyltransferase activity & 1 & 1 & \\
\hline adenosylhomocysteinase activity & 1 & \\
\hline adenyl-nucleotide exchange factor activity & & \\
\hline alpha-amylase activity & & \\
\hline
\end{tabular}


(Table 3). Contd.....

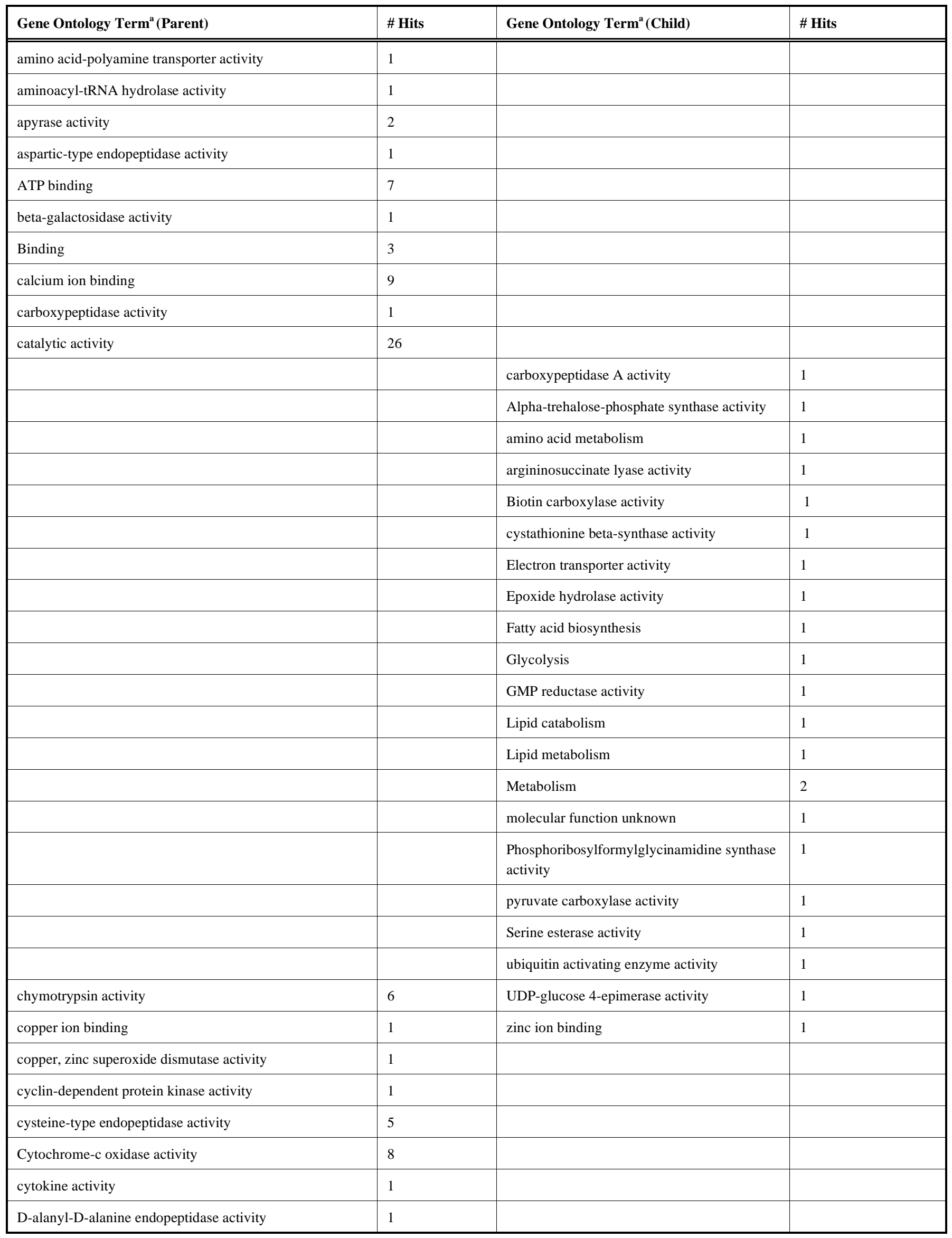




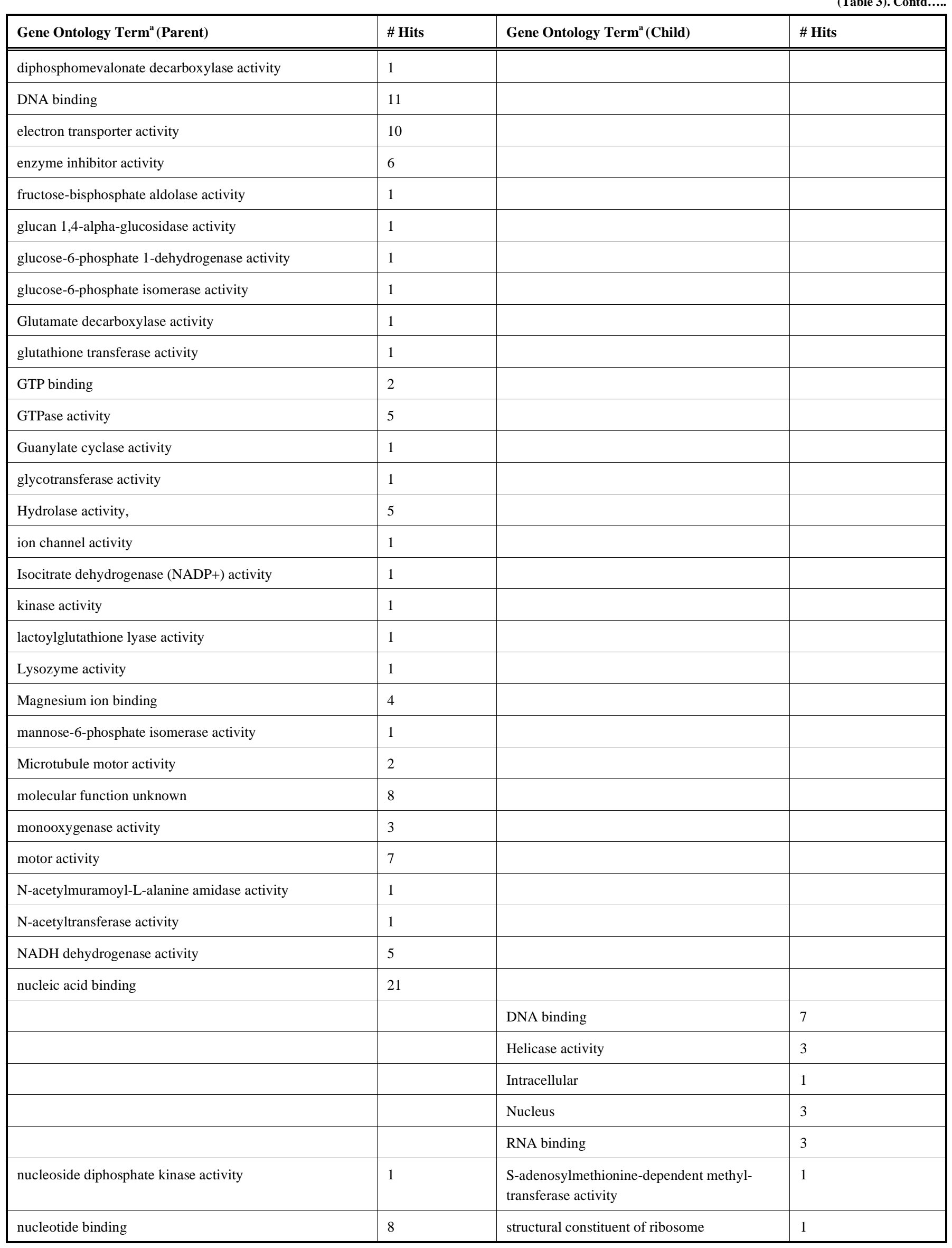


(Table 3). Contd.....

\begin{tabular}{|c|c|c|c|}
\hline Gene Ontology Term ${ }^{a}$ (Parent) & \# Hits & Gene Ontology Term ${ }^{a}$ (Child) & \# Hits \\
\hline odorant binding & 1 & & \\
\hline ornithine-oxo-acid transaminase activity & 1 & & \\
\hline Oxidoreductase activity & 1 & & \\
\hline oxygen transporter activity & 1 & & \\
\hline Peptidase activity & 1 & & \\
\hline peptidyl-prolyl cis-trans isomerase activity & 2 & & \\
\hline peroxidase activity & 2 & & \\
\hline phosphoglycerate dehydrogenase activity & 1 & & \\
\hline phosphoglycerate kinase activity & 1 & & \\
\hline phospholipase A2 activity & 2 & & \\
\hline Phosphoprotein phosphatase activity & 3 & & \\
\hline polypeptide $\mathrm{N}$-acetylgalactosaminyltransferase activity & 1 & & \\
\hline protein binding & 5 & & \\
\hline protein kinase activity & 2 & & \\
\hline protein phosphatase inhibitor activity & 1 & & \\
\hline protein phosphatase type 1 activity & 1 & & \\
\hline protein tyrosine phosphatase activity & 1 & & \\
\hline protein-L-isoaspartate O-methyltransferase activity & 1 & & \\
\hline Pyridoxal kinase activity & 1 & & \\
\hline receptor activity & 2 & & \\
\hline RNA binding & 14 & & \\
\hline RNA polymerase II transcription factor activity & 1 & & \\
\hline serine-type endopeptidase activity & 4 & & \\
\hline serine-type endopeptidase inhibitor activity & 1 & & \\
\hline signal transducer activity & 1 & & \\
\hline Structural constituent of cell wall & 2 & & \\
\hline Structural constituent of ribosome & 21 & & \\
\hline Structural molecule activity & 7 & & \\
\hline Succinate dehydrogenase activity & 1 & oxidoreductase activity & 1 \\
\hline sugar binding & 1 & & \\
\hline sugar porter activity & 1 & & \\
\hline Threonine endopeptidase activity & 1 & & \\
\hline transcription factor activity & 1 & & \\
\hline transferase activity & 1 & & \\
\hline translation elongation factor activity & 9 & & \\
\hline translation initiation factor activity & 3 & & \\
\hline translation release factor activity & 1 & & \\
\hline transporter activity & 5 & & \\
\hline tRNA binding & 1 & & \\
\hline tRNA ligase activity & 4 & & \\
\hline tubulin-tyrosine ligase activity & 1 & & \\
\hline Total & 241 & & \\
\hline
\end{tabular}

${ }^{a}$ Classification is hierarchical: indented terms are children [c] of parent terms [p] listed above. Functional assignments of Psyllid EST sequences are inferred from electronic evidence using top 5 BLASTX hits with an $E$-value of $\leq-10$ generated from NCBI's nr database. Definition terms according to The Gene Ontology Consortium. 
Table 4. Comparison of the Assembled Psyllid ESTs to Five Genomes

\begin{tabular}{|c|c|c|c|c|c|}
\hline Species: & C. elegans & D. melanogaster & H. sapiens & A. mellifera & A. aegypti \\
\hline \multicolumn{6}{|l|}{ E-Values } \\
\hline$\leq \mathrm{e}-100$ & $3.50 \%$ & $4.00 \%$ & $3.90 \%$ & $5.50 \%$ & $4.70 \%$ \\
\hline$\leq \mathrm{e}-50$ & 41 & 48 & 43 & 54 & 52 \\
\hline \multirow[t]{2}{*}{$\leq \mathrm{e}-20$} & 61 & 66 & 69 & 63 & 68 \\
\hline & $43.30 \%$ & $44.00 \%$ & $45.10 \%$ & $38.60 \%$ & $40.20 \%$ \\
\hline \multirow[t]{2}{*}{$\leq \mathrm{e}-10$} & 34 & 30 & 35 & 37 & 41 \\
\hline & $24.10 \%$ & $20.00 \%$ & $22.90 \%$ & $22.70 \%$ & $24.30 \%$ \\
\hline
\end{tabular}

Counts and percentages of significant matches over four categories of E-values, comparing Psyllid sequences to Nematode, Fruit fly, Human, Honey bee, and Mosquito, respectively Psyllid data compared to each species separately, BLASTX analysis. No significant differences between species at each E-value.

2-Biological Process, 3- Molecular Functions). Psyllid EST's in relation to their putative protein homologues (BLASTX) had the greatest overall similarity to the mosquito, A. aegypti (homology matches better than E-value $\leq$ e-10). Individual pairwise comparisons to the five genome databases resulted in similar distribution patterns of homology matches at each of four categories of E-values (ranges were from $\leq$ e-10 to $\leq$ $\mathrm{e}-20$ to $\leq \mathrm{e}-50$ to $\leq \mathrm{e}-100)$. There were no significant differences within each E-value analysis. Chi Square significance probability levels at $0.05, \mathrm{df}=4 ; 1 \leq \mathrm{E}-100,1.588$. $1 \leq \mathrm{E}-50$, 2.630, $1 \leq \mathrm{E}-20,0.691,1 \leq \mathrm{E}-10,1.842$ (Table 4). The high rate of non significantly matched sequences which estimates potential unique sequences within the $D$. citri cDNA library is most likely to be an overestimation due to several factors, such as computer alignment parameters, as well as low quality internal sequences [29]. Moreover, assembled sequences may have lacked an open reading frame because they were too short causing cDNAs to consist mostly or entirely of a noncoding region (e.g., 3' untranslated region [16, 30, 31]. Annotation will be improved by obtaining more, and longer assembled sequences resulting in a higher proportion of sequences that contain a protein coding region. Longer assembled sequences result in an increase of significant matches as shown to be true for cDNA's from plants [30].

\section{Genes of Interest}

The psyllid genome size was estimated using Feulgen densitometry to be $0.35 \mathrm{pg}, \mathrm{SD}=0.0291$ (Hunter and ArdilaGarcia unpublished results) using five individuals, as in Hardie et al. [32](2002). The distribution of EST sequences sorted by enzyme class shows that Hydrolases make up the majority of enzymes identified (64\%) with the Oxidoreductase class second (14\%) (Table 5). Within the Hydrolase class identified transcripts occurred across 10 subclasses (Table 6). Also of interest was the identification of several specific enzymes. Aspartic protease (EC 3.4.23) (Psyllid sequence, partial 1100 bp, DN468794, DN467920), similar to vertebrate Cathepsin D. The percent similarities of amino acid sequence of the aspartic protease from $D$. citri to other organisms, averaged $57 \%$ similarity, E-value, e e $^{-84}$ (BLASTX analyses top three - 57\% - Mosquito, Aedes aegypti, AAA29350; 57\% - Bee, Apis mellifera, XM392857; 58\% Japanese flying squid, Todarodes pacificus, BAD15111, AB106552.1). Also identified were cDNA's with similarities to Glutathione S-transferase (BLASTX analysis, partial 672 bp, average E-value, $\mathrm{e}^{-46}$ ) (DN466244, DN466232), and to cytochrome $\mathrm{P} 450$ monooxygenase, with similarity to the Cyp4 gene family, (TBLASTX analysis, partial $687 \mathrm{bp}$, average E-value, $\mathrm{e}^{-21}$ ) (DN466541, DN466559, DN466560, DN468646, DN469747).

\section{DISCUSSION}

While the Asian Citrus Psyllid, Diaphorina citri, is an economically important pest of citrus, overall very little has been published concerning psyllid genomics. While the results reported here provide an important dataset, albeit a small dataset covering $\sim 4 \%$ of the total potential transcripts in psyllids, these data provide the impetus for further functional genomics approaches to be undertaken to advance the understanding of psyllid biology. Currently two more cDNA libraries are being sequenced one from psyllid midguts and another from adult male testes (Hunter in progress). These results have received attention from the Florida and California Citrus Industries, to consider funding a full metagenomic study of the Asian citrus psyllid to identify all associated microbes to address questions surrounding the severe Huanglongbing disease of citrus which threatens citrus production worldwide (Hunter, http://www.ars.usda.gov/pandp/people /people.htm?personid=11768; http://www.doacs.state.fl.us/ pi/hlb_conference/Proceedings.pdf). Even within the Hemiptera, only recently are efforts completing full genome projects. In 2005, two Hemiptera genome projects were started which targeted: 1) the Pea aphid, Acyrthosiphon pisum, Family Aphididae, which was released early 2009 http://www.aphidests.org/; http://www.aphidbase.com/ aphidbase/ and 2) the insect vector of Chagas Disease, Rhodnius prolixus, Family Reduviidae, http://www. vectorbase.org/index.php. Completion of these genomes will greatly aid efforts working on hemipteran pests. One of the major advantages of EST projects is that they provide imme- 
Table 5. Enzymatic Classification of Asian Citrus Psyllid Sequences

\begin{tabular}{|c|c|c|c|}
\hline EC \# & Class & Subclass & \# sequences \\
\hline 1.14 & Oxidoreductase & Oxygen & 4 \\
\hline 1.3 & Oxidoreductase & Acting on the $\mathrm{CH}-\mathrm{CH}$ Group of Donors & 3 \\
\hline 1.7 & Oxidoreductase & Acting on other Nitrogenous Compounds as Donors & 1 \\
\hline 1.9 & Oxidoreductase & Acting on a Heme Group of Donors & 8 \\
\hline 2.1 & Transferase & Transferring One-Carbon Groups & 2 \\
\hline 2.3 & Transferase & Acyltransferases & 1 \\
\hline 2.6 & Transferase & Transferring nitrogenous groups & 1 \\
\hline 2.7 & Transferase & Transferring phosphorus-containing groups & 19 \\
\hline 3.1 & Hydrolases & Acting on ester bonds & 11 \\
\hline 3.2 & Hydrolases & Glycosidases & 11 \\
\hline 3.3 & Hydrolases & Acting on ether bonds & 2 \\
\hline 3.4 & Hydrolases & Acting on peptide bonds (Peptidases) & 13 \\
\hline 3.5 & Hydrolases & Acting on Carbon-Nitrogen Bonds, other than Peptide Bonds & 1 \\
\hline 4.6 & Lyases & Phosphorus-Oxygen Lyases & 1 \\
\hline 5.1 & Isomerases & Racemases and Epimerases & 1 \\
\hline 5.2 & Isomerases & cis-trans-Isomerases & 2 \\
\hline 5.3 & Isomerases & Intramolecular Oxidoreductases & 4 \\
\hline 6.1 & Ligases & Forming Carbon-Oxygen Bonds & 4 \\
\hline 6.3 & Ligases & Forming Carbon-Nitrogen Bonds & 6 \\
\hline 6.4 & Ligases & Forming Carbon-Carbon Bonds & 1 \\
\hline \multicolumn{3}{|l|}{ Total } & 258 \\
\hline
\end{tabular}

Unassembled EST's by hierarchical classification. Functional assignments of Psyllid sequences described are inferred from electronic evidence using top 5 BLASTX hits with an $E$ value of $\leq-10$ generated from NCBI's nr database. Definition according to The International Union of Biochemistry and Molecular Biology's Enzyme classification system.

diate information on psyllid biology and provide sequences for further functional genomics [16, 17, 33]. While the number of functional genes is not correlated to genome size [34] $\mathrm{http} / /$ /genomesize.com/results/) the psyllid genome was estimated to be $(\sim 0.35 \mathrm{pg})$ about a third the size of the whitefly Bemisia argentifolii ( 1.1 pg [33], three and a half times smaller than the glassy-winged sharpshooter $(\sim 1.24 \mathrm{pg}$,
Hunter unpublished results) and slightly smaller than the pea aphid genome at $464 \mathrm{Mb}$ (http://www.hgsc.bem.tmc.edu/ projects/aphid/). Comparison of the psyllid dataset to five genomes, nematode, fruit fly, human, honey bee, and mosquito, demonstrated that EST annotation results in similar distributions across other organisms, most likely due to the nature of these datasets each identifying common genes early 
in their production and each relying on strong comparisons among 'finished' genomes. Thus they are dependent upon a common annotation knowledge approach. As the annotations increase within these and other genome databases so will the ability to better compare and annotate new sequences through in silico analyses. Furthermore, the high incidence of 'no significant' and 'unknown protein' matches in EST datasets also demonstrates the need for further efforts on insects and arthropods to produce and to characterize more sequences from emerging EST and genome projects. As more genes, transcripts, and proteins are characterized the ability for rapid and accurate in silico annotations increases. While these advances are the cornerstone of the ability to compare sequences and functions through in silico analyses, the benefits from this and similar studies are the increased genomic data from psyllids which elucidates the genetic basis of psyllid biology. Continued work will rapidly advance the use and application of this information into the development of novel management strategies against these agricultural pests to reduce the spread of HLB disease in citrus trees.

\section{Targets of Interest within the D. citri cDNA Database}

While this study has focused on adult psyllids which disperse and spread HLB, there were other transcripts identified which provide important guidance for future research on psyllid biology. These include proteins that are critical for function and development of psyllid brain, nerve and synaptic transmission, muscle formation, reproduction of sperm and eggs, and the development of insecticide resistance (refer to Tables 2, 3). The Aspartic protease transcript identified is similar to vertebrate Cathepsin D, the function of which is thought to mediate the processing of yolk proteins in the oocyte. Aspartic proteases are reported to have important functions in the production of viable eggs [35, 36], and may prove useful in expanding our understanding of egg development in psyllids. Additionally the identification of transcriptional members within specific metabolic pathways broadens our knowledge of how $D$. citri evolved to feed specifically on citrus and its' near relatives. The ability of $D$. citri to detoxify citrus allelochemicals, along with the potential for the rapid development of insecticide resistance is of interest in the development of new management practices. Several enzymes identified are known to function in the metabolic breakdown of toxins. Different organisms use a variety of reactions to metabolize an amazing variety of organic molecules [37-40]. These reactions usually render toxic compounds more hydrophilic, thus generally less toxic and more easily excreted from the body [41]. The ability of insects to detoxify phytotoxins in plants probably evolved as many insects broadened their host range and encountered these defensive chemistries. However, insects continue to demonstrate their ability to metabolize xenobiotics, 'chemical substances that are foreign to the biological system' (def: $\mathrm{http}: / /$ medical.webends.com/kw/Xenobiotics). Examples of this are studies of P450-based insecticide resistance which have been shown to occur in most insect pests [38, 42, 43]. Examples of these transcripts reported from other insects which were also identified in D. citri include: Glutathione Stransferase, and several cytochrome P450 monooxygenases which include a transcript from the Cyp4 gene family. [4449]. Genes within the Cyp 4 family play a role in the development of insecticide resistance in Lepidoptera, Helicoverpa armigera [46], Coleoptera, Diabrotica virgifera [48], and Diptera, Anopheles gambiae [47, 50] and may similarly be examined for their role in the development of insecticide resistance in psyllids.

Table 6. Classification of E.C. Subclass 3.6 Hydrolases, Psyllid Unassembled EST's by Hierarchical Classification

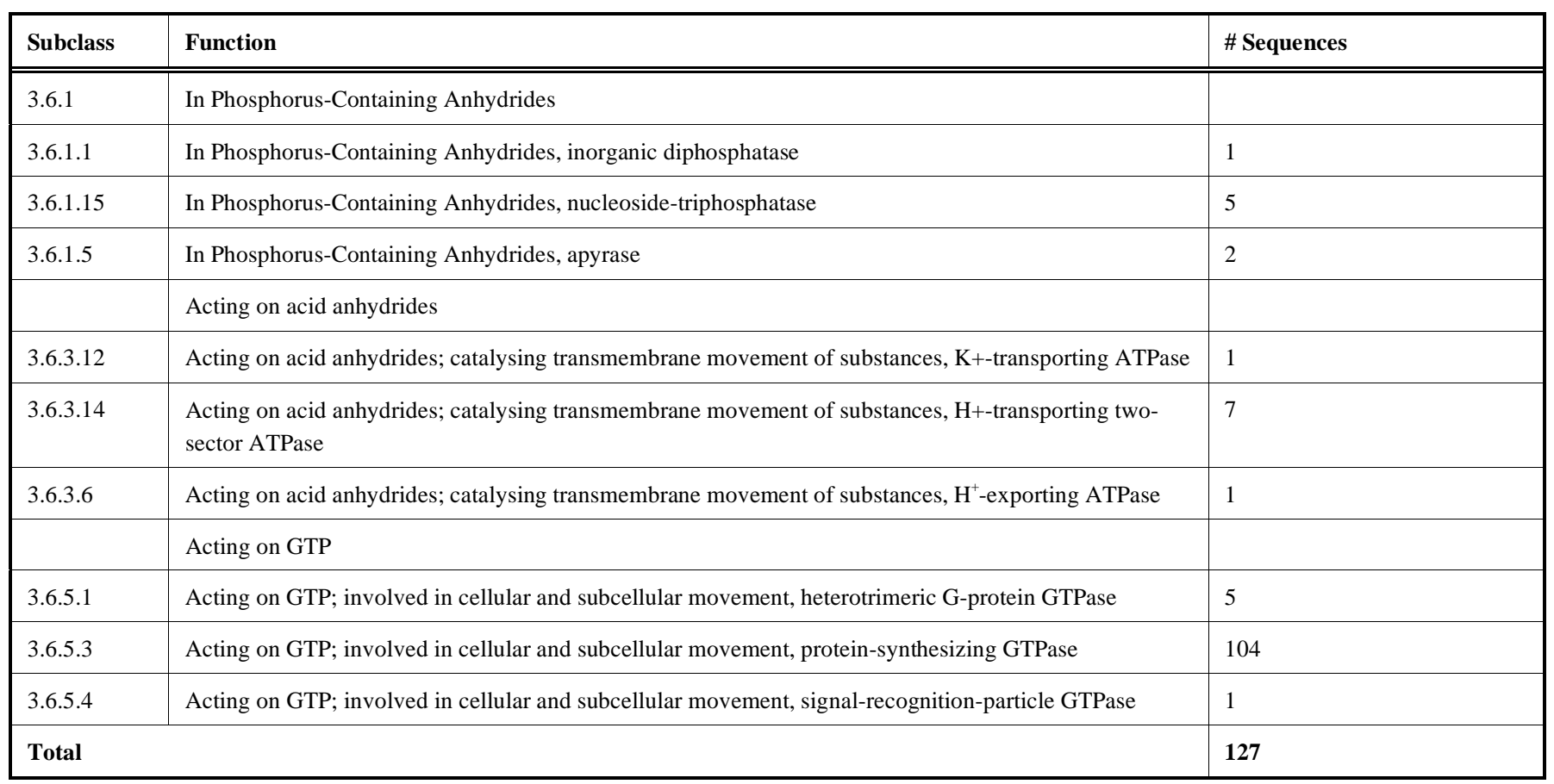

Functional assignments of Psyllid sequences described are inferred from electronic evidence of top 5 BLASTX hits with an $E$-value of $\leq-10$ generated from NCBI's nr database Definitions according to The International Union of Biochemistry and Molecular Biology's Enzyme classification system. 


\section{CONCLUSIONS}

We provide the first functional genomics project for psyllids (Hemiptera: Psyllidae). The set of sequences developed in this study makes available a cDNA sequence dataset for an important disease vector, the Asian citrus psyllid, D. citri, which is rapidly spreading Huanglongbing disease across the USA. The availability of these sequences opens the door for further investigations into important questions regarding $D$. citri biology, development, insecticide resistance, and disease interactions.

\section{ACKNOWLEDGMENTS}

We thank P.M. Dang, Genomics lab, ARS, U.S. Horticultural Research Laboratory, Ft. Pierce, FL, for sequencing, L.E. Hunnicutt, Biological Science Technician, U.S. Horticultural Research Laboratory, Ft. Pierce, FL for cDNA library construction and data analysis, and K. Moulton, T. Panvil, Biological Science Technicians, U.S. Horticultural Research Laboratory, Ft. Pierce, FL for sample collections and preparations.

\section{REFERENCES}

[1] Halbert SE, Manjunath KL. Asian citrus psyllid (Sternorrhyncha: Psyllidae) and greening disease of citrus: a literature review and assessment of risk in Florida. Florida Entomol 2004; 87: 330-53.

[2] Bastianel C, Garnier-Semancik M, Renaudin J, Bové JM, Eveillard S. Diversity of "Candidatus Liberibacter asiaticus," based on the omp gene sequence. Appl Environ Microbiol 2005; 71: 6473-8.

[3] Garnier M, Jagoueix-Eveillard S, Cronje PR, Le Roux GF, Bové JM. Genomic characterization of a Liberibacter present in an ornamental rutaceous tree, Calodendrum capense, in the Western Cape province of South Africa. Proposal of 'Candidatus Liberibacter africanus subsp. capensis'. Int J Syst Evol Microbiol 2000; 50: 211925.

[4] Halbert SE, Niblitt CL, Manjunath KL, Lee RF, Brown LG. Proceedings of the International Society of Citriculture IX Congress; Establishment of two new vectors of citrus pathogens in Florida 1016-1017, 2000 Dec 3-7; Orlando Florida, USA. 2003.

[5] Li W, Hartung JS, Levy L. Quantitative real-time PCR for detection and identification of Candidatus Liberibacter species associated with citrus Huanglongbing. J Microbiol Methods 2006; 66: $104-15$.

[6] Bové JM. Huanglongbing: a destructive, newly-emerging, centuryold disease of citrus. J Plant Pathol 2006; 88: 7-37.

[7] Mead FW. Florida Department of Agriculture and Consumer Services, Division of Plant Industry. Originally published FDACS/DPI Entomol Cir No. 180. Pub Number: EENY-33. Copyright 19982005 University of Florida; USA. 2005

[8] Newman T, de Bruijn FJ, Green P, et al. Genes galore: a summary of methods for accessing results from large-scale partial sequencing of anonymous Arabidopsis cDNA clones. Plant Physiol 1994; 106: 1241-55.

[9] Cooke R, Raynal M, Laudie M, et al. Further progress towards a catalogue of all Arabidopsis genes: analysis of a set of 5,000 nonredundant ESTs. Plant J 1996; 9: 101-24.

[10] Rounsley SD, Glodek A, Sutton G, et al. The construction of Arabidopsis expressed sequence tag assemblies: a new resource to facilitate gene identification. Plant Physiol 1996; 112: 1177-83.

[11] Marutani-Hert M, Hunter WB, Katsar CS, Sinisterra XH, Hall DG, Powell CA. Reovirus-like sequences isolated from adult Asian citrus psyllid, (Hemiptera: Psyllidae: Diaphorina citri). Florida Entomol 2009; 92: 314-20.

[12] Valles SM, Strong CA, Dang PM, et al. A picorna-like virus from the red imported fire ant, Solenopsis invicta: initial discovery, genome sequence, and characterization. Virology 2004; 328: 151-7.

[13] Valles SM, Strong CA, Hunter WB, et al. Expressed sequence tags from the red imported fire ant, Solenopsis invicta: annotation and utilization for discovery of viruses. J Invertebr Pathol 2008; 99: 7481.

[14] Hunter WB, Katsar CS, Chaparro JX. (2006) Molecular analysis of capsid protein of Homalodisca coagulata virus -1. A new leafhop- per-infecting virus from the glassy-winged sharpshooter. J Insect Sci 2008; Available from: http://www.insectscience.org/6.28/

Hunnicutt LE, Hunter WB, Cave RD, Powell CA, Mozoruk JJ. Genome sequence and molecular characterization of Homalodisca coagulata virus-1, a novel virus discovered in the glassy-winged sharpshooter (Hemiptera: Cicadellidae). Virology 2006; 350: 6778.

[16] Hunter WB, Dang PM, Bausher MG, et al. Aphid biology: Expressed genes from alate Toxoptera citricida, the brown citrus aphid. J Insect Sci 2003; Available from: http://www.insectscience.org/3.23/

[17] Tagu D, Prunier-Leterme N, Legeai F, et al. Annotated expressed sequence tags for studies of the regulation of reproductive modes in aphids. Insect Biochem Mol Biol 2004; 34: 809-22.

[18] Nakabachi A, Shigenobu S, Sakazume N, et al. Transcriptome analysis of the aphid bacteriocyte, the symbiotic host cell that harbors an endocellular mutualistic bacterium, Buchnera. Proc Natl Acad Sci USA 2005; 102: 5477-82.

[19] Wilson ACC, Dunbar HE, Davis GK, Hunter WB, Stern DL, Moran NA. A duel-genome microarray for the pea aphid, Acyrthosiphon pisum, and its obligate bacterial symbiont, Buchnera aphidicola. BMC Genomics 2006; 7: 50, doi:10.1186/1471-21647-50.

[20] DeRisi JL, Iyer VR, Brown PO. Exploring the metabolic and genetic control of gene expression on a genomic scale. Science 1997; 278: 680-6

[21] Loftus SK, Chen Y, Gooden G, et al. Informatic selection of a neural crestmelanocyte cDNA set for microarray analysis. Proc Natl Acad Sci USA 1999; 96: 9277-80.

[22] Ruan Y, Gilmore J, Conner T. Towards Arabidopsis genome analysis: monitoring expression profiles of 1,400 genes using cDNA microarrays. Plant J 1998; 15: 821-33.

[23] Sabater-Muñoz B, Legeai R, Rispe C, et al. Large-scale gene discovery in the pea aphid Acyrthosiphon pisum (Hemiptera). Genome Biol 2006; 7: R21, doi:10.1186/gb-2006-7-3-r21.

[24] Rafalski JA, Hanafey M, Miao GH, et al. New experimental and computational approaches to the analysis of gene expression. Acta Biochim Polonica 1998; 45: 929-34

[25] Ewing RM, Kahla AB, Poirot O, Lopez F, Audic S, Claverie JM. Large-scale statistical analyses of rice ESTs reveal correlated patterns of gene expression. Genome Res 1999; 9: 950-9.

[26] Zhu Q, Arakane Y, Beeman RW, Kramer KJ, Muthukrishnan S. Characterization of recombinant chitinase-like proteins of Drosophila melanogaster and Tribolium castaneum. Insect Biochem Mol Biol 2008; 38: 467-77.

[27] Audic S, Claverie JM. The significance of digital gene expression profiles. Genome Res 1997; 7: 986-95.

[28] Strommer JN, Gregerson R, Vayda M. Methods in plant molecular biology and biotechnology. Boca Raton, Florida, USA: CRC Press 1993.

[29] White JA, Todd J, Newman T, et al. A new set of Arabidopsis expressed sequence tags from developing seeds: the metabolic pathway from carbohydrates to seed oil. Plant Physiol 2000; 124: 1582-94.

[30] Bausher M, Shatters R, Jr, Chaparro J, Dang P, Hunter W, Niedz R. An expressed sequenced tag (EST) dataset from Citrus sinensis L. Osbeck whole seedlings and the implications of further perennial source investigations. Plant Sci 2003: 165: 415-22.

[31] Whitfield CW, Band MR, Bonaldo MF, et al. Annotated expressed sequence tags and cDNA microarrays for studies of brain and behavior in the honey bee. Genome Res 2002; 12: 555-66.

[32] Hardie DC, Gregory TR, Hebert PDN. From pixels to picograms: a beginners' guide to genome quantification by Feulgen image analysis densitometry. J Histochem Cytochem 2002; 50: 735-49.

[33] Leshkowitz D, Gazit S, Reuveni E, et al. Whitefly (Bemisia tabaci) genome project: analysis of sequenced clones from egg, instar, and adult (viruliferous and non-viruliferous) cDNA libraries. BMC Genomics 2006; 7: 79, doi:10.1186/1471-2164-7-79.

[34] Gregory TR. The evolution of the genome. San Diego, USA: Elsevier 2005.

[35] Brooks S, Tyler CR, Carnevali O, Coward K, Sumpter JP. Molecular characterisation of ovarian cathepsin D in the rainbow trout, Oncorhynchus mykiss. Gene 1997; 201: 45-54.

[36] De Stasio R, Borrelli L, Kille P, Parisi E, Filosa S. Isolation, characterization and molecular cloning of cathepsin D from lizard 
ovary: changed in enzyme activity and mRNA expression throughout ovarian cycle. Mol Reprod Dev 1999; 52: 126-34.

[37] Feyereisen R. Molecular biology of insecticide resistance. Toxicol Lett 1995; 82: 83-90.

[38] Feyereisen R. Insect P450 enzymes. Annu Rev Entomol 1999; 44: 507-33.

[39] Scott JG. Cytochromes P450 and insecticide resistance. Insect Biochem Mol Biol 1999; 29: 757-77.

[40] Scott JG, Wen Z. Cytochromes P450 of insects: the tip of the iceberg. Pest Manag Sci 2001; 57: 958-67.

[41] Coon MJ, Vaz AD, Bestervelt LL. Peroxidative reactions of diversozymes. Fed Am Soc Exp Biol J 1996; 10: 428-34.

[42] Berge JB, Feyereisen R, Amichot M. Cytochrome P450 monooxygenases and insecticide resistance in insects. Philos Trans R Soc B Biol Sci 1998; 353: 1701-5.

[43] Hodgson E. Comprehensive insect physiology, biochemistry, and pharmacology. UK: Oxford: Pergamon Press 1985; Vol. 11.

[44] Enayati AA, Ranson H, Hemingway J. Insect glutathione transferases and insecticide resistance. Insect Mol Biol 2005; 14: 3-8.

[45] Francis F, Vanhaelen N, Haubruge E. Glutathione S-transferases in the adaptation to plant secondary metabolites in the Myzus persicae aphid. Arch Insect Biochem Physiol 2005; 58: 166-74.
[46] Pittendrigh B, Aronstein K, Zinkovski E, et al. Cytochrome P450 genes from Helicoverpa armigera: expression in a pyrethroidsusceptible and -resistant strain. Insect Biochem Mol Biol 1997; 27: 507-12.

[47] Ranson H, Nikou D, Hutchinson M, et al. Molecular analysis of multiple cytochrome P450 genes from the malaria vector, Anopheles gambiae. Insect Mol Biol 2002; 11: 409-18.

[48] Scharf ME, Parimi S, Meinke LJ, Chandler LD, Siegfried BD Expression and induction of three family 4 cytochrome P450 (CYP4)* genes identified from insecticide-resistant and susceptible western corn rootworms, Diabrotica virgifera virgifera. Insect $\mathrm{Mol}$ Biol 2001; 10: 139-46.

[49] Singh SP, Coronella JA, Benes H, Cochrane BJ, Zimniak P. Catalytic function of Drosophila melanogaster glutathione S-transferase DmGSTS1-1 (GST2) in conjugation of lipid peroxidation end products. Eur J Biochem 2001; 268: 2912-23.

[50] Amichot M, Brun A, Cuany A, et al. Induction of cytochrome P450 activities in Drosophila melanogaster strains susceptible or resistant to insecticides. Comp Biochem Physiol C Pharmacol Toxicol Endocrinol 1998; 121: 311-9.

(C) Hunter et al.; Licensee Bentham Open.

This is an open access article licensed under the terms of the Creative Commons Attribution Non-Commercial License (http://creativecommons.org/licenses/by-nc/3.0/) which permits unrestricted, non-commercial use, distribution and reproduction in any medium, provided the work is properly cited. 